\title{
COMPARATIVE FINE STRUCTURE OF EGGS OF AUTOGENOUS AND ANAUTOGENOUS CULEX PIPIENS (DIPTERA: CULICIDAE) By
}

\author{
BELAL A. SOLIMAN, MAHA K. TEWFICK AND NAHLA M. WASSIM
} Department of Zoology, Faculty of Science, Suez University, Suez, Egypt

Abstract

Culex $(C x$.) pipiens is the potential vector of human filariasis in Egypt. However, autoge- nous $C x$. pipiens may be less efficient vector of Wuchereria $(W$.) bancrofti in endemic areas of Egypt compared to anautogenous counterparts. In this study, an attempt was made to differentiate eggs of autogenous and anautogenous $C x$. pipiens using scanning electron micrographs. The results indicated that eggs of both species appear to be similar to great extent in surface morphology. Eggs of both forms are black and elongate-oval. Width is greatest at the anterior end. The posterior end is pointed. The micropylar disc is apparent with distinct edge. Exochorionic bridges are angular. Size of both eggs represented by length and width are comparable. In both eggs, length is greater than width. However, eggs of both forms can be distinguished from each other by the exochorionic bridges being longer and thinner in the autogenous eggs than in the anautogenous eggs.

Key words: Electron Microscope, autogenous, anautogenous, egg, Culex pipiens

\section{Introduction}

Mosquitoes act as vectors for several diseases including malaria and filaria (Parmanand et al, 2008). Despite centuries of control efforts, mosquito-borne diseases are flourishing worldwide (Tolle, 2009). Culex (Cx.) pipiens is common mosquito vector so many diseases in urban and suburban areas in the world (Soliman, 1995). It is incriminated as one of the principle vectors of filariasis, Rift Valley fever and other virus-borne diseases. Culex pipiens is a polytypic species that exist in autogenous and anautogenous forms (Spielman, 1967). Autogeny, the ability of a mosquito to mature an initial batch of eggs without blood feeding, is an alternative re-productive strategy with important implications for vector-borne disease transmission (Provost-Javier et al, 2010). Autogeny is associated with an inherent ability of autogenous mosquitoes to store more nutritional reserves than anautogenous counterparts. Those reserves are the precursors for oogenesis to produce the first egg clutch in autogenous females (Soliman et al, 1995). Elevated lipid content before emergence may play a role of inducing ovarian development in autogenous mosquitoes (Sawabe and Moribayashi, 2000). Larval food must be adequate and abundant, because the quality and quantity of it has a pronounced effect on the autogeny rate (Vinogradova and Karpova, 2006). However, autogenous $C x$. pipiens may be less efficient vector of Wuchereria $(W$.) bancrofti in endemic areas of Egypt compared to anautogenous counterparts (Hassan et al, 1994). The technology required for intervening effectively against vector-borne infection is based on systematic experimental research (Spielman, 2003). Relatively recent mosquito taxonomical studies rely on advanced tools including scanning electron microscopy. The morphometrical and morphological analysis of the egg attributes may be helpful in species confirmation as well as in differentiation between identical forms (Suman et al, 2011). The shape of the eggs is generally characteristic of the various genera. The pattern of impressed and raised markings on the outer chorion provides useful taxonomic characters. Suman et al. (2009) 
suggested that ecological variation may affect the morphometric attributes of the egg of $C x$. quinquefasciatus strains collected from different geographical areas. On the contrary, no environmental influence on the egg attributes of Anopheles (An.) darling was detected (Almeida et al, 2014).

Scanning electron microscopy was widely used to describe eggs of Haemagogus tropicalis (Alencar et al, 2008), Ochlerotatus albifasciatus (Santos-Mallet et al, 2009), Aedes (Ae.) scapularis (Dos Santos-Mallet et al, 2010), Psorophora albigenu (Pacheco et al, 2012), Sabethes cyaneus (SantosMallet et al, 2013) and Georgecraigius fluviatilis (Sarmento et al, 2014). An ultrastructural key was built for species identification of An. hyrcanus group eggs in Thailand based on eggs micrographs (Saeung et al, 2014).

The present research dealt with comparative study by scanning electron microscopy of surface morphology and morphometrics of Egyptian autogenous and anautogenous Cx. pipiens eggs.

\section{Materials and Methods}

Anautogenous $C x$. pipiens larvae were collected from a drainage canal in Suez Governorate. Autogenous Cx. pipiens larvae were collected from cement water basin located in the Garden of Ain Shams University. Larvae were raised in a walk-in insectary under optimum conditions of $27 \pm 2^{\circ} \mathrm{C}$ and fed on fish food till pupation. Emerged adults were allowed to mate for 24-48 hours. Anautogenous female mosquitoes were offered a blood meal followed by sucrose solution, while autogenous mosquitoes were fed on sucrose solution only. Eggs from either group were allowed to embryonate for 24 hours, and then fixed in bouin solution ac- cording to Linley et al. (1996). Eggs were then rinsed in three changes of $80 \%$ ethanol to remove picric acid, dehydrated through a continuing ethanol series and dried by the critical point method. Eggs were set with a fine artist's brush on stubs coated with carbon, dried, and then coated with gold.

Descriptions: Autogenous form (Figs 1 -2, Tab. 1)

Size: length (mean 494.75 $\pm 10.76 \mu \mathrm{m}, \mathrm{n}=4$ ) is greater than width (mean $98.50 \pm 14.15$ $\mu \mathrm{m})$, as indicated in length/width ratio (mean 5.37 \pm 0.85 ). Color: black

Shape: elongate-oval, width greatest at the anterior end, posterior end pointed. Micropylar collar: micropylar disc apparent, edge distinct (Fig.1a, b).

Posterior end: pointed compared to the anterior end (Fig. $1 \mathrm{c}, \mathrm{d}$ ), boundaries of outer chorionic cell fields angular (Fig. 2 e, f). Exochorionic bridge longer and thinner than anautogenous $\backslash$ (length $0.61 \pm 0.05 \mu \mathrm{m}$, width $0.21 \pm 0.01 \mu \mathrm{m})$.

Table 1: Dimensions of eggs of autogenous $(n=4)$ and anautogenous $(n=5)$ Culex pipiens

\begin{tabular}{|l|c|c|c|c|c|c|}
\hline \multirow{2}{*}{ Form } & \multicolumn{2}{|c|}{ Length $(\mu \mathrm{m})$} & \multicolumn{2}{c|}{ Width $(\mu \mathrm{m})$} & \multicolumn{2}{c|}{ L/W Ratio } \\
\cline { 2 - 7 } & Mean $\pm \mathrm{SE}$ & Range & Mean \pm SE & Range & Mean \pm SE & Range \\
\hline Autogenous & $494.75 \pm 10.76$ & $477-523$ & $98.50 \pm 14.15$ & $60.7-129$ & $5.37 \pm 0.85$ & $4.05-7.86$ \\
\hline Anautogenous & $480.60 \pm 8.49$ & $461-503$ & $88.64 \pm 7.03$ & $63.6-103$ & $5.61 \pm 0.60$ & $4.57-7.9$ \\
\hline
\end{tabular}

Table 2: Dimensions of exochorionic bridges of autogenous $(n=6) \&$ anautogenous $(n=8)$ Culex pipiens

\begin{tabular}{|l|c|c|c|c|}
\hline \multirow{2}{*}{ Form } & \multicolumn{2}{|c|}{ Length $(\mu \mathrm{m})$} & \multicolumn{2}{c|}{ Width $(\mu \mathrm{m})$} \\
\cline { 2 - 5 } & Mean $\pm \mathrm{SE}$ & Range & Mean $\pm \mathrm{SE}$ & Range \\
\hline Autogenous & $0.61 \pm 0.05$ & $0.47-0.79$ & $0.21 \pm 0.01$ & $0.18-0.23$ \\
\hline Anautogenous & $0.46 \pm 0.02$ & $0.40-0.60$ & $0.30 \pm 0.02$ & $0.24-0.42$ \\
\hline
\end{tabular}

Anautogenous form (Tab.1): Micropylar collar: micropylar disc apparent, Size: length (mean $480.60 \pm 8.49 \mu \mathrm{m}, \mathrm{n}=5$ ) greater than width (mean $88.64 \pm 7.03 \mu \mathrm{m}$ ), a indicated in length/width ratio (mean 5.61 \pm 0.60 ). Color: Black. Shape: elongate-oval, width greatest at the anterior end, posterior end pointed, edge distinct (Fig. 3 a, b). Posterior end: 
pointed compared to the anterior end (Fig. 3 c, d). Exochorionic bridges angular (Fig. 4 e, f): Outer chorionic reticulum: shorter $(\mathrm{P}=$ $0.01)$ and thicker $(\mathrm{P}=0.002)$ than autogenous (length $0.46 \pm 0.02 \mu \mathrm{m}$, width $0.30 \pm 0.02 \mu \mathrm{m}$ ).

\section{Discussion}

Culex pipiens $L$. is the most widespread mosquito vector in the temperate regions (Gomes et al, 2009). This species consists of two forms, denoted molestus and pipiens that exhibit important behavioural and physiological differences. Culex pipiens pipiens and $C x$. pipiens Forskål molestus differ little morphologically, but their biological features differ significantly. Culex pipiens Forskål molestus form is autogenous, stenogamous and anthropophilic, whereas pipiens form is anautogenous, eurygamous and capable of diapause. Both forms occur in the sympatry almost throughout the whole area of distribution (Vinogradova, 2000). In the U.S.A., Cx. pipiens bioformes, Cx. pipiens form pipiens and $C x$. pipiens form molestus, as well as $C x$. quinquefasciatus, reside in distinct but overlapping ecological niches and readily hybridize in areas where they coexist (Ciota et al, 2013). Culex molestus is a phenotypic and physiological variant of Cx. pipiens (Harbach, 2012). The sympatric presence of different $C x$. pipiens biotypes was also confirmed in Portugal, Western Europe (Osório et al, 2014).

Culex molestus Forskål was originally described from Egypt as a distinct species in 1775. It was recorded in Europe from the 1920s, first in London, England, and later in many other countries (Mihalyi, 1965; Vino-gradova, 2000). In the temperate zone, both forms differ in their habitats. The urban mo-squitoes develop throughout the year in underground sites flooded by polluted waters, e.g. in the basements of houses and underground tunnels. In this zone both forms are strongly isolated from one another. Such situation was observed in London, England (Byrne and Nichols, 1999) and in the Upper Rhein Valley in Germany (Becker et al, 1999). The degree of isolation between the two forms decreased in the southern of Europe, the two forms live in sympatry in surface habitats which promotes hybridization between the two species. As a result, populations with intermediate biological characteristics have been described. For instance, Egyptian populations of $C x$. pipiens are relatively homogenous (Farid et al, 1991; Vi-nogradova and Shaikevich, 2007). Until the relatively recent application of molecular identification tools, identification of $C x$. pipiens f. pipiens and Cx. pipiens f. molestus relied on expressed ecological characteristics, including autogeny, host preference and stenogamy (Danabalan et al, 2012). From the epidemiological point of view, autogenous $C x$. pipiens may be less efficient vector of $W$. bancrofti in endemic areas of Egypt compared to anautogenous counterparts (Hassan et al, 1994).

Similarly, preference of $C x$. molestus to delay blood feeding until up to day 8 following emergence may re- duce their relative importance as a vector of arboviruses (Kassim et al, 2012).

The present results indicated that $C x$. pipiens eggs of autogenous and anautogenous forms appear to be similar to great extent in surface morphology. This result is supported by the fact that there is no limitation for hybridization between autogenous and anautogenous $C x$. pipiens mosquitoes in Egypt due to the lack of premating and postmating barriers (Nudelman et al, 1988; Gad et al, 1995). Egyptian populations of $C x$. pipiens are confirmed to be relatively homogenous (Farid et al, 1991; Vinogradova and Shaikevich, 2007). However, the exochorionic bridge served to differentiate the two forms. The exochorionic bridge of autogenous egg was longer and thinner than that of anautogenous egg. Previous studied agreed that outer egg chorion had served to recognize $A n$. dunhami from the related $A n$. trinkae Faran and An. nuneztovari (Lounibos et al, 1997) and to differentiate between $C x$. tritaeniorhynchus and $C x$. quinquefasciatus (Suman et al, 2008) and between Ae. aegy- 
pti and Ae. albopictus (Suman et al, 2011).

Soliman et al. (2014) suggested that the two forms autogenous and anautogenous $A e$. (Ochlerotatus) caspius of Egypt are two distinct species depending on morphometric differences in the ultrastructure micrographs of eggs. In the present study, it can be concluded that the morphometric variations of the egg micrographs of the two Egyptian autogenous and anautogenous $C x$. pipiens forms are not sufficient to judge that this study were dealing with two distinct species and confirmed the hybridization theory resulting in populations with intermediate biological characteristics (Farid et al, 1991; Gad et al, 1995; Vinogradova and Shaikevich, 2007).

\section{Conclusion}

Future study must focus on the recent application of molecular tools to solve the problem of Cx. pipiens complex in Egypt.

\section{References}

Alencar, J, Degallier, N, Guimarães, AE, Costa, JM, Marques, W de A, et al, 2008: Scanning electron microscopy of the egg of Haemagogus tropicalis. J. Am. Mosq. Control Assoc. 24, 1:16-20.

Almeida, F, Suesdek, L, Motoki, MT, Bergo, ES, Sallum, MA, 2014: Morphometric comparisons of the scanning electron micrographs of the eggs of Anopheles (Nyssorhynchus) darlingi Root (Diptera: Culicidae). Acta Trop. 706X, 14:232-0.

Becker, N, Jöst, A, Weitzel, T, Robinson, WH, et al, 1999: Exploiting the biology of urban mosquitoes for their control. Proc. $3^{\text {rd }}$ Int. Conference on Urban Pests. Czech Univ. Agriculture, Prague, Czech Republic.

Byrne, K, Nichols, RA, 1999: Culex pipiens in London Underground tunnels: differentiation between surface and subterranean populations. Heredity (Edinb). 82, Pt 1:7-15.

Ciota, AT, Chin, PA, Kramer, LD, 2013: The effect of hybridization of Culex pipiens complex mosquitoes on transmission of West Nile virus. Parasit. Vectors 23, 6, 1:305.

Danabalan, R, Ponsonby, DJ, Lintoni, YM, 2012: A critical assessment of available molecular identification tools for determining the status of Culex pipienss.l. in the United Kingdom. J. Am. Mosq. Control Assoc. 28, 4:S68-74.
Dos Santos-Mallet, JR, Müller, GA, Gleiser, RM, Alencar, J, Marques, Wde A, et al, 2010: Scanning electron microscopy of the eggs of Aedes scapularis from southern South America. J. Am. Mosq. Control Assoc. 26, 2:205-9.

Farid, HA, Gad, AM, Spielman, A, 1991: Genetic similarity among Egyptian populations of Culex pipiens (Diptera: Culicidae). J. Med. Entomol. 28, 2:198-204.

Gad, AM, Abdel Kader, M, Farid, HA, Hassan, AN, 1995: Absence of mating barriers between autogenous and anautogenous Culex pipiens L. in Egypt. J. Egypt. Soc. Parasitol. 25, 1:63-71.

Gomes, B, Sousa, CA, Novo, MT, Freitas, FB, Alves, R, et al, 2009: Asymmetric introgression between sympatric molestus and pipiens forms of Culex pipiens (Diptera: Culicidae) in the Comporta region, Portugal. BMC Evol. Biol. 9:262.

Harbach, RE, 2012: Culex pipiens: species versus species complex taxonomic history and perspective. J. Am. Mosq. Control Assoc. 28, 4:S10-23.

Hassan, AN, Merdan, A, Gad, AM, 1994: Vector competence of autogenous and anautogenous Culex pipiens mosquitoes for Wuchereria bancrofti. J. Egypt. Pub. Hlth. Assoc. 69, 5/6: 347-58.

Kassim, NF, Webb, CE, Russell, RC, 2012: Is the expression of autogeny by Culex molestus Forskal (Diptera: Culicidae) influenced by larval nutrition or by adult mating, sugar feeding, or blood feeding? J. Vector Ecol. 37, 1:162-71.

Linley, JR, Lounibos, LP, Conn, J, Duzak, D, Nishimura, N, 1996: A description and morphometric comparison of eggs from eight geographic populations of the South American malaria vector Anopheles (Nyssorhynchus) nuneztovari (Diptera: Culicidae). J. Am. Mosq. Control Assoc.12:275-92.

Lounibos, LP, Duzak, D, Linley, JR, 1997: Comparative egg morphology of six species of the Albimanus section of Anopheles (Nyssorhynchus) (Diptera: Culicidae). J. Med. Entomol. 34, 2:136-55.

Nudelman, S, Galun, R, Kitron, U, Spielman, A, 1988: Physiological characteristics of Culex pipiens populations in the Middle East. Med. Vet. Entomol. 2, 2:161-9.

Osório, HC, Zé-Zé, L, Amaro, F, Nunes, A, Alves, MJ, 2014: Sympatric occurrence of $\mathrm{Cu}$ lex pipiens (Diptera, Culicidae) biotypes pipiens, 
molestus and their hybrids in Portugal, Western Europe: feeding patterns and habitat determinants. Med. Vet. Entomol. 28, 1:103-9.

Pacheco, JB, Santos-Mallet, JR, Guimarães, AÉ, Costa, JM, Alencar, J, 2012: Ultrastructure and morphometry of the egg of Psorophora albigenu Lutz, 1908 (Diptera: Culicidae). Micron 43, 2/3: 418-21

Parmanand, B, Naik, K, Dixit, V, Gupta, AK, Kataria, OM, et al, 2008: Prevalence of mosquito species in Chhura block of Raipur district of Chhattisgarh state. J. Commun. Dis. 40, 2: 139-46.

Provost-Javier, KN, Chen, S, Rasgon, JL, 2010: Vitellogenin gene expression in autogenous Culex tarsalis. Insect Mol. Biol. 19, 4: 423-9.

Saeung, A, Hempolchom, C, Yasanga, T, Otsuka, Y, Thongsahuan, S, et al, 2014: Scanning electron microscopy of Anopheles hyrcanus group (Diptera: Culicidae) eggs in Thailand and an ultrastructural key for species identification. Parasitol. Res. 113, 3:973-81.

Santos-Mallet, JR, Gleiser, RM, Alencar, J, Marques, Wde A, Sarmento, JS, et al, 2009: Scanning electron microscopy of the egg of Ochlerotatus albifasciatus (Diptera: Culicidae). J. Med. Entomol. 46, 5:980-5.

Santos-Mallet, J, Sarmento, JS, Alencar, J, Müller, GA, Oliveira, EM, et al, 2013: Scanning electron microscopy of eggs of Sabethescyaneus. J. Am. Mosq. Control Assoc. 29, 1:648.

Sarmento, JS, Marcondes, CB, Alencar, J, Oliveira, EM, De Mello, CF, et al, 2014: Scanning electron microscopy of eggs of Georgecraigius fluviatilis (Lutz) (Diptera: Culicidae, Aedini). Zootaxa. 3784, 5:591-5.

Sawabe, K, Moribayashi, A, 2000: Lipid utilization for ovarian development in an autogenous mosquito, Culex pipiens molestus (Diptera: $\mathrm{Cu}-$ licidae). J. Med. Entomol. 37, 5: 726-31

Soliman, BA, 1995: Comparative exsheathment of microfilariae of Wuchereria bancrofti in certain mosquito species. J. Egypt. Soc. Parasit ol. 25, 1:207-12.

Soliman, MA, Seif, AI, Hassan, AN, AbdelHamid, ME, Mansour, MA, et al, 1995: Nutritional reserves in autogenous and anautogenous populations of Culex pipiens and Aedes caspius (Diptera: Culicidae). J. Egypt. Soc. Parasitol. 25, 2:499-507.
Soliman, BA, Wassim, NM, Linley, JR, 2014: Distinguishing the two forms of Egyptian Aedes (Ochlerotatus) caspius Pallas species (Diptera: Culicidae) by ultrastructure micrographs of eggs. J. Egypt. Soc. Parasitol. 44, 1:71-7.

Spielman, A, 1967: Population structure in the Culex pipiens Complex of mosquitos. Bull. WHO 37:271-6.

Spielman, A, 2003: Research approaches in the development of interventions against vector-borne infection. J. Exp. Biol. 206:3727-34.

Suman, DS, Shrivastava, AR, Pant, SC, Parashar, BD, 2011: Differentiation of Aedes aegypti and Aedes albopictus (Diptera: Culicidae) with egg surface morphology and morphometrics using scanning electron microscopy. Arthropod Struct. Dev. 40, 5:479-83.

Suman, DS, Shrivastava, AR, Parashar, BD, Pant, SC, Agrawal, OP, et al, 2008: Scanning electron microscopic studies on egg surface morphology and morphometrics of Culex tritaeniorhynchus and Cx. quinquefasciatus (Diptera: Culicidae). Parasitol. Res. 104, 1: 173-6.

Suman, DS, Shrivastava, AR, Parashar, BD, Pant, SC, Agrawal, OP, et al, 2009: Variation in morphology and morphometrics of eggs of Culex quinquefasciatus mosquitoes from different ecological regions of India. J. Vector Ecol. 34, 2:191-9.

Tolle, MA, 2009: Mosquito-borne diseases. Curr. Probl. Pedatr. Adolesc. Hlth. Care 39, 4: 97-140.

Vinogradova, EB, 2000: Culex pipiens pipiens mosquitoes: Taxonomy, Distribution, Ecology, Physiology, Genetics, Applied Importance and Control. Pensoft Ser. Parasitologica No 2. Pensoft Publishers, Sofia, Moscow.

Vinogradova, EB, Karpova, SG, 2006: Cultivation of the mosquito Culex pipiens pipiens $\mathrm{F}$. molestus (Diptera, Culicidae) without blood feeding. Parazitologiia 40, 3:306-11.

Vinogradova, EB, Shaikevich, EV, 2007: Morphometric, physiological and molecular characteristics of underground populations of the urban mosquito Culex pipiens Linnaeus f. molestus Forskål (Diptera: Culicidae) from several areas of Russia. Euro Mosq. Bull. 22:17-24. 

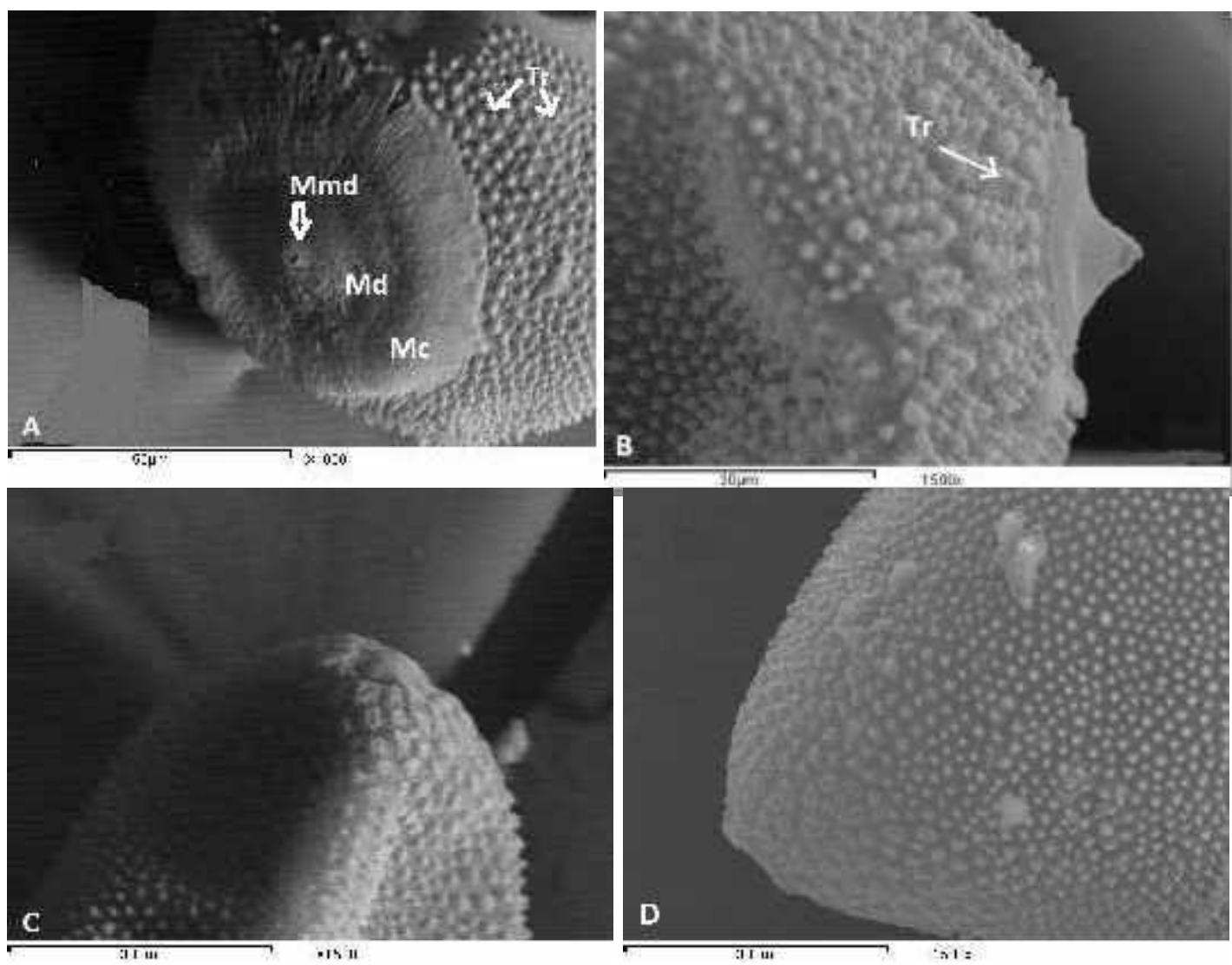

Fig. 1: Scanning electron micrographs of egg surface of autogenous form of Culex pipiens. A: anterior end; B: micropylar region; C: posterior end; D: posterior end, lateral view. (Mc: micropylar corolla, Md: micropylar disc, Mmd: micropylar mound, Tr: tubercular rows) 

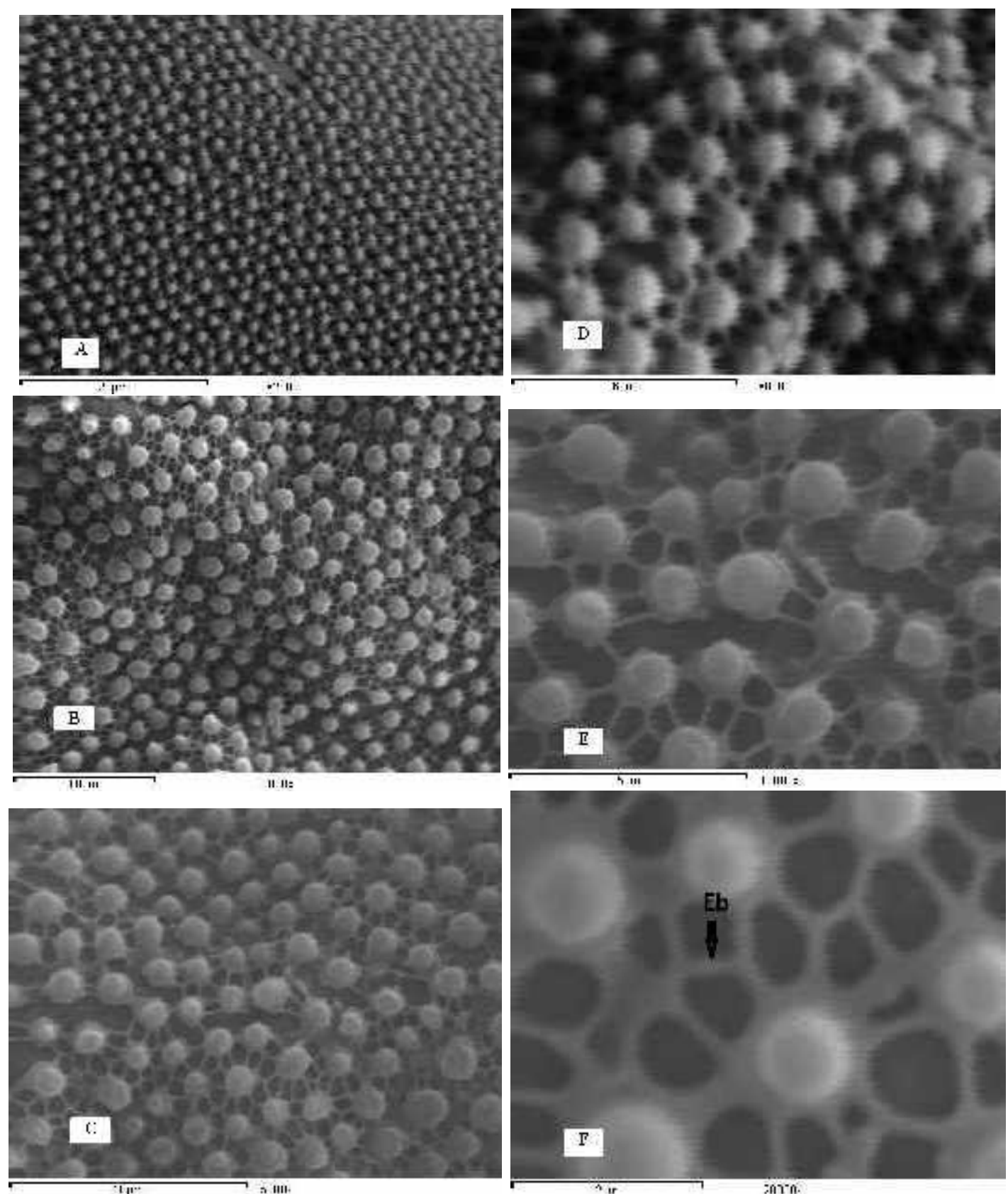

Fig. 2: Autogenous form of $C x$. pipiens. A-F: progressive magnification of egg surface. (Eb: exochorionic bridge) 

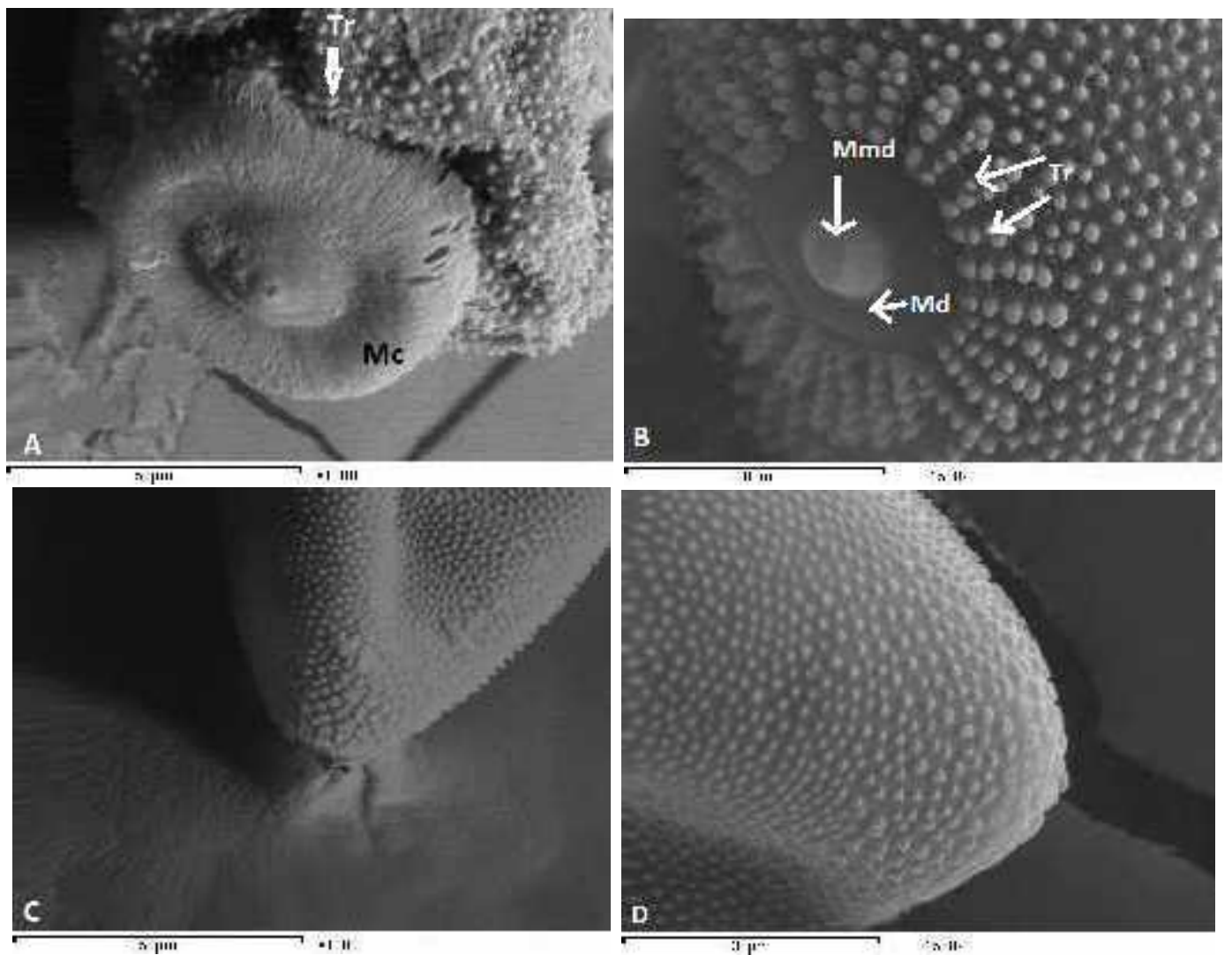

Fig. 3: Anautogenous form of Culex pipiens. A: anterior end; B: micropylar disc; C: posterior end; D: posterior end, lateral view. (Mc: micropylar corolla, Md: micropylar disc, Mmd: micropylar mound, Tr: tubercular rows) 

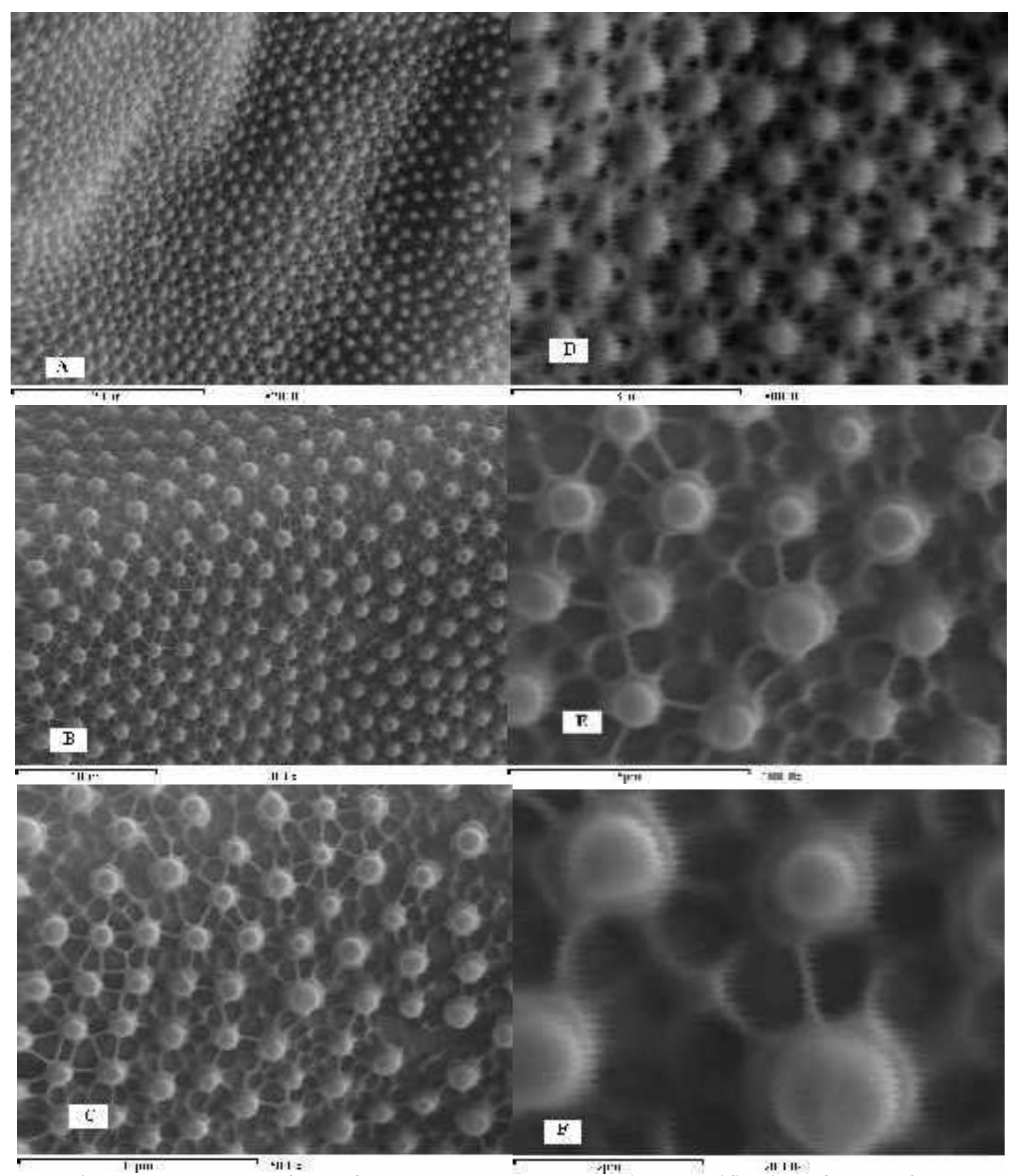

Fig. 4: Anautogenous form of $C x$. pipiens. A- F: progressive magnification of egg surface. 